\title{
Personalized Preventive Plan in General Medicine
}

\author{
Olfa Harzallah Hellara ${ }^{1^{*}}$, Asma Sriha Belguith ${ }^{2}$, Sourour Ncibi ${ }^{1}$ and Brahem Noura ${ }^{1}$ \\ ${ }^{1}$ Department of General Medicine, Hospital of Bembla, Monastir, Tunisia \\ ${ }^{2}$ Department of Epidemiology and Preventive Medicine, University Hospital of Monastir, Tunisia \\ "Corresponding author: Olfa Harzallah Hellara, Department of General Medicine, Hospital of Bembla, Monastir, Tunisia, Tel: +21698407127; E-mail: \\ harzallah.olfa@gmail.com
}

Received date: November 09, 2017, Accepted date: November 16, 2017, Published date: November 21, 2017

Copyright: @ 2017 Hellara OH, et al. This is an open-access article distributed under the terms of the Creative Commons Attribution License, which permits unrestricted use, distribution, and reproduction in any medium, provided the original author and source are credited.

\begin{abstract}
Background: In recent years, prevention has become increasingly important in General Medicine (GM) and has become the focus of several debates worldwide. The evolution of the Tunisian society urges to seek a preventive approach then a Specific Preventive Consultation (SPC) became a necessity.

Objective: We aimed at determining the output of a SPC within a consultation of GM.

Method: A descriptive study was carried out for 9 months (from November 2016 to July 2017) in a primary care at Monastir governorate. A SPC was incorporated into the daily care consultations. An appropriate questionnaire, highlighting cardiovascular, carcinogenic and depressive risk factors, was sent to 313 consultants who agreed and adapted actions have been proposed to them. We have analyzed follow up results for screened participants according to personalized preventive plan (PPP).

Results: For 313 participants, $48(15 \%)$ have high cardio vascular risk (HCVR). Obesity, physical inactivity, smoking and alcohol consumption were notified respectively among $30.5 \%, 19 \%, 19 \%$ and $7 \%$ of our population. Familial ATCD of breast cancer was present in $2.2 \%$, anxiety in $32 \%$ and depression in $23 \%$ of our patients. All screened participants provided with a personalized prevention plan (PPP). Therapeutic education was performed for 140 patients; awareness to a tobacco free environment for 155 and 71 mammography was prescribed for women at risk from which one returned with cancer.

Conclusion: SPC has improved the knowledge and practices of patients. It also identified several risk factors and especially breast cancer at an early stage. We concluded that Personalized Preventive Plan can be performed in GM to improve and promote health.
\end{abstract}

Keywords: General medicine; Medical consultation; Preventive medicine

\section{Introduction}

The profession of family physician is changing. The European definition of general practice improves health promotion and education through appropriate and effective intervention. Each country or region seeks to find a "compromise" of what should be an appropriate and effective response to the demands and expectations of care of an aging population with chronic diseases and the inflationary financial cost of specialized medicine.

In recent years, prevention has become an increasingly important part of general medicine (GM) and has become the focus of several debates on new health laws in several countries [1]. Thus, the introduction of a specific preventive consultation (SPC) will aim to establish the risk factors that will prevent certain pathologies; to reach as many patients as possible, to improve the health of patients and especially to value general medicine. The establishment and systematization of these specific consultations would make it possible to link care and prevention and would be an important source of feedback on the health status of the population.
This would allow for a better understanding and assessment of the health needs of our country. We aimed at describing the contribution of the SPC on screening risk factor of cardiovascular diseases, cancer and depression and on educating population.

\section{Method}

\section{Study area}

Bembla is one of the 13 delegations of Monastir governorate. It covered 44,685 inhabitants representing $16 \%$ of Monastir population [2]. It is served by a local hospital and six primary health center which are provided by six family doctors, a pediatrician and a dentist.

In 2016, the number of consultants at these structures was 65086. We have performed our study in the GM center of the local hospital which assured 9763 consultations per year.

\section{Study design}

This is a cross-sectional descriptive study carried out during 9 months from November 2016 to July 2017 including 313 participants. 
Page 2 of 7

\section{Study population}

We have included subjects aged 18 to 65 years. During the study period 7231 patients have consulted from them 3253 have inclusion criteria. Information for SPC was performed by poster and during the interview.

An appointment was given according to patient agreement. The SPC was realized one day per week including 7 participants per day. Thus, 313 patients benefited from a SPC including a personalized preventive project (PPP).

\section{Data collection}

The data was collected using a questionnaire including the Sociodemographic information, clinical examination data (personal or family ATCDs, risk factors of cardiovascular diseases, cancer and depression, weight, height, waist circumference). Anxiety and depression were assessed using the HAD (Hospital Anxiety and Depression Scale) scale.

For the assessment of high cardiovascular risk (HCVR), the summative method was used [3]. A patient with HCVR is defined as any patient with multiple vascular risk factors which when added together increase the risk of ischemic cardiovascular complications [4].

\section{Statistical analysis}

Data analyze was performed using SPSS 21.0. Qualitative variables were expressed as numbers and percentages, quantitative variables by means and standard deviation.

\section{Results}

\section{Socio-demographic and psychological characteristics of the study population}

A total of 313 patients have beneficed of SPC. The average age was $40 \pm 12$ years. Women accounted for $73.8 \%$ of consultants and patients without partners represented $27.4 \%$ of the participants, $58.7 \%$ felt they had an unstable social life.

Anxiety and depression were expressed respectively, by $32 \%$ and $23 \%$ of our consultants (Table 1 ).

\begin{tabular}{|c|c|c|c|}
\hline \multicolumn{2}{|l|}{ Characteristics } & \multirow{2}{*}{$\begin{array}{l}\mathbf{N} \\
155\end{array}$} & \multirow{2}{*}{\begin{tabular}{|l} 
Percentage (\%) \\
49.5 \\
\end{tabular}} \\
\hline Age & $18-40$ & & \\
\hline & $41-65$ & 158 & 50.5 \\
\hline \multirow[t]{2}{*}{ Sex } & Female & 231 & 73.8 \\
\hline & Male & 82 & 26.2 \\
\hline \multirow[t]{5}{*}{ Profession } & Student & 19 & 6 \\
\hline & Housewife & 39 & 12.5 \\
\hline & Worker & 195 & 62.3 \\
\hline & Middle/upper framework & 43 & 25.7 \\
\hline & Retired & 17 & 5.4 \\
\hline \multirow[t]{3}{*}{ Marital status } & Single & 73 & 23.3 \\
\hline & Married & 227 & 72.5 \\
\hline & Widowed/divorced & 13 & 4.1 \\
\hline \multirow[t]{4}{*}{ Social situation } & Unstable work & 106 & 33.8 \\
\hline & Insecurity at work & 102 & 32 \\
\hline & Social isolation & 32 & 10.2 \\
\hline & Unstable social life & 184 & 58.7 \\
\hline \multirow[t]{2}{*}{ Score HAD } & $\mathrm{HADA}>11$ & 100 & 32.1 \\
\hline & HADD $>11$ & 72 & 23 \\
\hline
\end{tabular}

Table 1: Socio-Demographic and Psychological characteristics of the study population.

\section{Cardiovascular risk factor}

$30 \%$ of the participants were obese, $5.7 \%$ were overweight and $19 \%$ were sedentary (practiced physical activity less than $30 \mathrm{~min} /$ week). Active smoking was notified in $54 \%$ of men. We have screened 39 cases of hypertension, 7 cases of type 2 diabetes, 6 cases of moderate fasting hyperglycemia and 58 cases of dyslipidemia.

High risk for cardiovascular disease was detected in $15 \%$ of our study population (Table 2). 
Citation: Hellara OH, Belguith AS, Ncibi S, Noura B (2017) Personalized Preventive Plan in General Medicine. J Gen Pract (Los Angel) 5: 341.

\begin{tabular}{|c|c|c|c|}
\hline \multicolumn{2}{|l|}{ Characteristics } & \multirow{2}{*}{$\begin{array}{l}\mathbf{N} \\
4\end{array}$} & \multirow{2}{*}{$\begin{array}{l}\text { Percentage (\%) } \\
1.2\end{array}$} \\
\hline FRCVX not modifiable & Women 65 ans or older & & \\
\hline Age correlated with sex & Men 55 ans or older & 20 & 6.3 \\
\hline \multirow[t]{2}{*}{ Atcd vascular accident } & Personal & 6 & 1.9 \\
\hline & Family & 15 & 4.7 \\
\hline \multirow{4}{*}{$\begin{array}{l}\text { FRCVX indirectly modifiable } \\
\text { Obesity }\end{array}$} & Overweight & 18 & 5.7 \\
\hline & Moderate Obesity & 49 & 15.6 \\
\hline & Severe Obesity & 43 & 13.7 \\
\hline & Morbid Obesity & 4 & 1.2 \\
\hline \multirow[t]{3}{*}{ Inactivity } & $<30 \mathrm{~min} /$ week & 60 & 19 \\
\hline & $30 \mathrm{~min}-2$ hour/week & 197 & 62 \\
\hline & $>2$ hour $30 \mathrm{~min} /$ week & 56 & 17.8 \\
\hline \multirow{3}{*}{$\begin{array}{l}\text { FRCVX directy modifiable } \\
\text { Tobacco }\end{array}$} & Active & 61 & 19 \\
\hline & Men & 45 & $45 / 82$ \\
\hline & Passive & 94 & 30 \\
\hline \multirow[t]{3}{*}{ Hta } & HTA under treatment & 23 & 7.3 \\
\hline & TAS $\geq 14$ and/or $T A D \geq 9$ & 11 & $11 / 23$ \\
\hline & HTA detected ${ }^{*}$ & 39 & $39 / 290$ \\
\hline \multirow[t]{5}{*}{ Diabetes } & Diabetes under treatment & 14 & 4.4 \\
\hline & $\mathrm{Hb}$ glycated $\leq 7 \%$ & 8 & $8 / 14$ \\
\hline & $\mathrm{Hb}$ glycated $>7 \%$ & 6 & $6 / 14$ \\
\hline & Diabetes diagnosed $^{\star *}$ & 7 & $7 / 299$ \\
\hline & Moderate hyperglycemia on an empty stomach ${ }^{\star \star *}$ & 6 & $6 / 299$ \\
\hline \multirow[t]{4}{*}{ Dyslipidemia } & ATCD Perso of dyslipidemia & 11 & 3.5 \\
\hline & $\mathrm{CH} / \mathrm{HDL} \leq 4$ & 7 & $7 / 11$ \\
\hline & $\mathrm{CH} / \mathrm{HDL}>4$ & 4 & $4 / 11$ \\
\hline & Dyslipidemia detected $(\mathrm{CH} / \mathrm{HDL}>4)$ & 58 & 18.5 \\
\hline \multirow[t]{2}{*}{ Protective factors diet } & Rich in fruits and vegetables & 253 & 81.1 \\
\hline & Rich in olive oil & 184 & 58.9 \\
\hline Physical activity & $>2$ hour $30 \mathrm{~min} /$ week & 56 & 17.8 \\
\hline \multicolumn{4}{|c|}{$\begin{array}{l}\text { "HTA detected among non-hypertensive patients ( } \mathrm{n}=290): \text { TAS } \geq 14 \text { and/or TAD } \geq 9 \mathrm{mmHg} \text {; } \\
\text { " Diabetes detected among non-diabetics ( } 299) \text { : dextro } \geq 2 \text { or } 2 \text { glycemia } \geq 1.26 \mathrm{mmol} / \mathrm{l} \\
{ }^{* * * *} \text { Moderate hyperglycemia on an empty stomach: glycemia } \geq 1.1 \text { and } \leq 1.25 \mathrm{mmol} / \mathrm{l}\end{array}$} \\
\hline
\end{tabular}

Table 2: Distribution of cardio-vascular risk factors.

\section{Cancer risk factors}

The average exposure to passive smoking was over 2 hours per day for $30 \%$ of patients.
The half of patients consumed more than 15 times a month meat and protein products. Salts and nitrites were consumed on a daily basis between 15 and 30 times/month by $23 \%$ of the consultants. 
Citation: Hellara OH, Belguith AS, Ncibi S, Noura B (2017) Personalized Preventive Plan in General Medicine. J Gen Pract (Los Angel) 5: 341.

Alcohol consumption was reported by only $7 \%$ of participants. Helical bacteria pylori infection was noted in $9.9 \%$ of participants.

Protective factors was notified among $81.2 \%$ (high fiber diet) and $17.8 \%$ (physical activity $>2$ hour $30 \mathrm{~min} /$ week) in our population.

\section{Personalized Preventive Plan (PPP)}

Several actions have been put in place following preventive consultations.
Then, $85 \%$ of smokers had minimal counseling and $15 \%$ were referred to smoking cessation clinic awareness to a tobacco free environment was offered for 155 participants (Tables 3 and 4).

Therapeutic education was performed for 140 patients. 71 mammography was prescribed for women at risk from which one returned with cancer and referred to specialists (Figure 1).

\begin{tabular}{|c|c|c|c|}
\hline \multicolumn{2}{|l|}{ Characteristics } & \multirow{2}{*}{$\begin{array}{l}\mathbf{N} \\
61\end{array}$} & \multirow{2}{*}{\begin{tabular}{|l} 
Percentage (\%) \\
19
\end{tabular}} \\
\hline Smoking habit & Active & & \\
\hline & Passive & 94 & 30 \\
\hline \multirow[t]{2}{*}{ Diet } & Rich in meat & 160 & 51.1 \\
\hline & Rich in salts and nitrites & 72 & 23 \\
\hline \multirow[t]{2}{*}{ Alcohol } & Occasional & 21 & 6.7 \\
\hline & Everyday & 1 & 0.3 \\
\hline \multirow[t]{2}{*}{ Inactivity } & Physical activity $<30 \mathrm{~min} /$ week & 60 & 19 \\
\hline & $\begin{array}{l}\text { Physical activity between } 30 \mathrm{~min} \text { and } 2 \\
\text { hour /week }\end{array}$ & 197 & 62 \\
\hline \multirow[t]{3}{*}{ Infectious environmental factors } & $\mathrm{HP}^{+}$ & 31 & 9.9 \\
\hline & IST & 5 & 1.5 \\
\hline & Hepatitis B & 3 & 0.9 \\
\hline \multirow[t]{4}{*}{ Genetic factors } & ATCD Personal breast cancer & 7 & 2.2 \\
\hline & ATCD Breast cancer in the family & 7 & 2.2 \\
\hline & ATCD Colorectal cancer in the family & 1 & 0.3 \\
\hline & ATCD Prostate cancer in the family & 2 & 0.6 \\
\hline \multirow[t]{2}{*}{ Protective factors } & Diet rich in fibres & 253 & 81.2 \\
\hline & Physical Activity $>2$ hour $30 \mathrm{~min} /$ week & 56 & 17.8 \\
\hline
\end{tabular}

Table 3: Distribution of risk factors for cancer.

\begin{tabular}{|c|c|c|c|}
\hline \multicolumn{2}{|l|}{ Characteristics } & \multirow{2}{*}{$\begin{array}{l}\mathbf{N} \\
155\end{array}$} & \multirow{2}{*}{$\begin{array}{l}\text { Percentage (\%) } \\
49\end{array}$} \\
\hline Anti-smoking intervention & Sensitization to a tobacco-free environment & & \\
\hline & Minimal advice & 52 & $52 / 61$ \\
\hline & Anti-tobacco consultation & 9 & $9 / 16$ \\
\hline \multicolumn{2}{|l|}{ Physical activity } & 313 & 100 \\
\hline \multicolumn{2}{|l|}{ Food Hygiene } & 227 & 72 \\
\hline \multirow[t]{3}{*}{ Therapeutic education } & & 140 & 44 \\
\hline & Individual & 140 & 44 \\
\hline & Group & 47 & 15 \\
\hline Para clinical examinations & & 31 & 9.9 \\
\hline
\end{tabular}




\begin{tabular}{|c|c|c|c|}
\hline & Mammogram on normal breast exam & 67 & 21.4 \\
\hline & Mammogram on pathological breast exam & 4 & 1.2 \\
\hline & Breast Cancer detected & 1 & $1 / 71$ \\
\hline & Colonoscopy & 2 & 0.6 \\
\hline & Fibroscopy & 18 & 5.7 \\
\hline & Biological report & 64 & 20.4 \\
\hline \multicolumn{2}{|l|}{ Vaccination $^{*}$} & 4 & 1.2 \\
\hline \multicolumn{2}{|l|}{ Prescription of vitamin D } & 28 & 8.9 \\
\hline \multirow[t]{3}{*}{ Psychological support } & & 104 & 33.2 \\
\hline & Psychological care in the front line & 102 & 32.5 \\
\hline & Psychological care in psychiatry & 2 & 0.6 \\
\hline \multicolumn{2}{|l|}{ Homeopathic treatment } & 11 & 3.5 \\
\hline
\end{tabular}

Table 4: Description of personalized preventive plan.

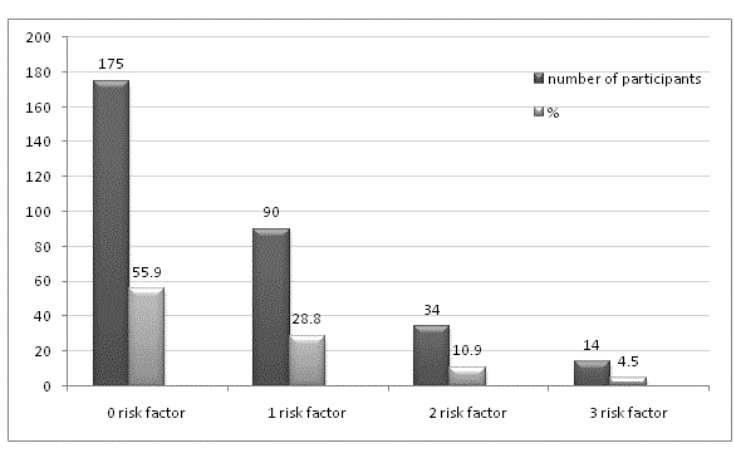

Figure 1: Distribution of cumulative number of conventional cardio-vascular-risk among PPP Participants.

\section{Discussion}

The most effective way to reduce the incidence of these diseases would be the establishment of a national collective prevention strategy. In our work, we have tried to circumvent the pathologies whose prevention is possible and especially relevant in general medicine [5]. Three subjects were explored and defined by their risk factors; vascular accidents, cancers and anxiety and depression.

\section{Evaluation of cardiovascular risk}

Few figures are available on the prevalence and management of patients with HRCV. Our study identified 48 patients among the 313 to HRCV with a rate of $15 \%$. Destombe C has established a rate of $30.4 \%$ for HRCV in their study including population aged 50 to 85 years [6]. Taking into account the addiction of risk factors, we will take the risk factors one by one and then propose a personalized prevention plan [7].

\section{Obesity and sedentary lifestyle}

Having $70 \%$ of women with a waist circumference $>88 \mathrm{~cm}$ and $17 \%$ of men>102 cm represents a revealing indicator of a rather obese population. Our population is represented by $30.5 \%$ obese and the $5.7 \%$ overweight. At the same time, we found that $19 \%$ of the consultants maintain a daily physical activity of less than $30 \mathrm{~min}$ per week.

\section{Smoking}

In our population, tobacco affects $54 \%$ of men. Minimal advice or motivational supports were provided. According to the Heart and Stroke Foundation, by halting smoking, a person reduces the risk of a heart attack related to smoking by half after only one year $[8,9]$.

\section{The HTA}

Since the questionnaire is not distributed on the day of chronic consultation, the patients generally come for acute pathologies. Among 23 patients with hypertension, we found 11 of them with systolic or diastolic greater than 14 or 9 . Considering that adequate management of hypertension decreases the risk of stroke by $40 \%$ and that of infarction by $15 \%$, our intervention was based mainly on therapeutic education. In addition, 39 of the 290 (13.5\%) consultants who did not recognize themselves as hypertensive and in whom a 15 days profile under a salt free diet confirmed HTA.

\section{Diabetes}

Among our patients, $4.4 \%$ were diabetics, $42 \%$ of whom had $\mathrm{HbA} 1 \mathrm{c}>$ to $7 \%$. In addition, this preventive consultation was able to detect 7 new diabetics among the 299 non diabetics, which represents $2.3 \%$ of our population, and 6 cases of moderate fasting hyperglycemia. Hence the need for screening which according to the American Diabetes Association should be systematically performed in adults of any age who are overweight or obese and who have one or more risk factors for diabetes [10]. 


\section{Dyslipidemias}

We defined dyslipidemia as any increase in the ratio of $\mathrm{CH} / \mathrm{HDL}>4$ (SCORE scale). Our study found 64 consultants with dyslipidemia of which $90 \%$ did not take an adequate daily treatment. The multicenter study MONALISA showed that despite recommendations, 53\% of patients with hypercholesterolemia received no treatment. During our work we encourage a hypo-lipid and a drug therapy was recommended $[11,12]$.

\section{Evaluation of the carcinogenic risk}

In Tunisia, cancer accounts for $16 \%$ of all deaths [13].

\section{Smoking}

Chronic smoking is one of the leading causes of preventable mortality and is the cause of one in three cancers. Our intervention was with $19 \%$ of our consultants of which $14 \%$ were addressed to the department of Preventive Medicine of the Fattouma Bourguiba Hospital of Monastir.

\section{Alcohol}

Only 22 patients (7\%) reported drinking alcohol. It appears that alcohol consumption appears to be very limited among the population. Our role was mostly educational.

\section{Food}

The International Agency for Research on Cancer (IARC) evaluated the results of 800 studies that examined the consumption of red meats or meats and cancer. According to the report, the risk increases by $17 \%$ for each $100 \mathrm{~g}$ of red meat consumed per day and $18 \%$ for each $50 \mathrm{~g}$ of processed meat consumed each day. Our study, with $51 \%$ of consultants who consumed meat and cold meats more than 15 times a month, allowed us to emphasize education in order to reduce this consumption and divert it to food protectors [13].

\section{Overweight, obesity and physical inactivity}

Several studies have attempted to establish the relationship between obesity and cancer. Our intervention was mainly based on weight reduction and the preservation of daily physical activity.

\section{Other environmental factors}

Other factors were investigated in our study in relation to some specific cancers such as; stomach, liver and cervix cancer. Breast cancer, is the leading cause of cancer death in women and the fourth leading cause of death among Tunisian women of reproductive age. Our study found that $2.2 \%$ of consultants had a family-based ATCD for breast cancer. Our intervention was essentially a therapeutic education with regard to hormone therapy, and para-clinical screening tests in this population at risk, which allowed us to detect 1 case of breast cancer on 71 mammograms requested.

\section{Evaluation of depressive risk}

Depression is one of the most common psychiatric disorders in adults and especially a dramatic increase in suicide mortality. Our study was based on the HAD scale, which is a structured questionnaire of 14 items. We found that $32 \%$ of patients were anxious and $23 \%$ reported depressive responses with a HADD score greater than 11 .
These data prompt us to systematically detect the psychological problems of our patients on the front line as this is a main pillar in the preventive consultation.

\section{Personalized Prevention Plan (PPP)}

We have focused on three main areas of prevention:

\section{Primary prevention}

The focus has been on health education, aimed at changing behavior, lifestyles or the environment, in order to protect health. In our work, $16 \%$ and $49 \%$ of the consultants benefited from minimal advice and awareness of a tobacco-free environment. Food hygiene advice was provided to $72 \%$ and an incentive for daily physical activity was $100 \%$ indicated.

\section{Secondary prevention}

Such as technical prescriptive acts. In our work, $49 \%$ of consultants have benefited from various clinical examinations.

\section{Tertiary prevention}

It aims to reduce recurrences, complications and squeals, especially through therapeutic education of the patient. Since the launch of our consultation, group education sessions have been implemented on a daily and targeted basis and have attracted $15 \%$ of our population.

\section{Conclusion}

The general physician is a major player in preventive medicine. He is able to ensure the link between the individual and the community through his knowledge of individuals, their ability to assess the health status of a population in which he works. He relays, contextualizes and personalizes the public health messages of collective dimension in individualized messages, audible by each one because they are emitted in the language of each one. SPC has improved the knowledge and practices of patients. It also identified several risk factors and especially breast cancer at an early stage. We concluded that individual and collective prevention can be performed in GM to improve and promote health.

\section{Conflict of Interest}

The authors have nothing to disclose concerning this manuscript.

\section{Ethical Considerations}

The study was conducted under good clinical practice conditions and according to the ethical standards collections. Each patient in the study is assigned a unique identifying code and all documents labeled accordingly to maintain anonymity.

\section{References}

1. http://www.ins.tn/sites/default/files/13_manastir_0.pdf

2. Miranda S, Doucet J, Lévesque H, Benhamou Y (2017) Statins in primary prevention of cardiovascular disease. Rev Med Interne 17: 30608-30612.

3. Waeber G, Cornuz J, Gaspoz JM, Guessous I, Mooser V, et al. (2017) Precision medicine: A required approach for the general internist. Rev Med Suisse 13: 133-137. 
Citation: Hellara OH, Belguith AS, Ncibi S, Noura B (2017) Personalized Preventive Plan in General Medicine. J Gen Pract (Los Angel) 5: 341.

4. Destombe C, Capucine, Tavernier B (2016) Evaluation of cardiovascular risk in the population of a multi-professional care home. Lille.

5. http://www.who.int/cardiovascular_diseases/guidelines/

PocketGL.ENGLISH.AFR-D-E.rev1.pdf

6. http://care.diabetesjournals.org/content/suppl/

2015/12/21/39.Supplement_1.DC2/2016-Standards-of-Care.pdf

7. https://www.iarc.fr/en/media-centre/pr/2013/pdfs/pr223_E.pdf

8. El Ati J, Traissac P, Delpeuch F, Aounallah-Skhiri H, Béji C, et al. (2012) Gender obesity inequities in a large cross-sectional study in Tunisia. PLoS One 7: e48153.

9. Sinilnikova OM, Dondon MG, Eon-Marchais S, Damiola F, Barjhoux L, et al. (2016) GENESIS: A French national resource to study the missing heritability of breast cancer. BMC Cancer 16: 13 .
10. Trabelsi J, Kammoun S, Karray M, Feki H, Kassis M, et al. (2011) Study of the causes of death of women of reproductive age at the hospitals of Sfax. Tunis Med 89: 745-751.

11. Helmer C, Montagnier D, Peres K (2004) Descriptive epidemiology, risk factors, aetiology of depression of the elderly. Psychologie \& Neuropsychiatrie du Vieillissement 2: S7-S12.

12. Godard J (2009) General Medicine and Prevention. In: Bourdillon F, Prevention treaty. Medecine Sciences Flammarion, Paris pp: 356-363.

13. Bourdillon F, Mosnier A, Godard J (2008) Public health missions for general practitioners. Sante Publique 20: 489-500. 